\title{
Why Environmental Ethics Shouldn't Give Up on Intrinsic Value
}

\begin{abstract}
Katie McShane*
Recent critics (Andrew Light, Bryan Norton, Anthony Weston, and Bruce Morito, among others) have argued that we should give up talk of intrinsic value in general and that of nature in particular. While earlier theorists might have overestimated the importance of intrinsic value, these recent critics underestimate its importance. Claims about a thing's intrinsic value are claims about the distinctive way in which we have reason to care about that thing. If we understand intrinsic value in this manner, we can capture the core claims that environmentalists want to make about nature while avoiding the worries raised by contemporary critics. Since the distinction between intrinsic and extrinsic value plays a critical role in our understanding of the different ways that we do and should care about things, moral psychology, ethical theory in general, and environmental ethics in particular shouldn't give up on the concept of intrinsic value.
\end{abstract}

Lately there have been calls within environmental ethics to abandon the concept of intrinsic value (roughly and preliminarily, the value a thing has in its own right), and there seems to be a growing consensus that this concept is unhelpful for thinking about how and why the natural environment should matter to us. ${ }^{1}$ Andrew Light, Bruce Morito, Bryan Norton, and Anthony Weston, among others, have criticized discussions of intrinsic value for both assuming a flawed theory of value and distracting environmental ethicists from other more important issues. ${ }^{2}$ Of course, there are many different views about what

\footnotetext{
* Department of Philosophy and Religion, North Carolina State University, Campus Box 8103, Raleigh, NC 27695-8103. McShane's primary research interests are in environmental ethics and ethical theory. She thanks Elizabeth Anderson, Arthur Applbaum, Karen Bennett, Alan Carter, Stephen Darwall, Patrick Frierson, Eugene C. Hargrove, P. J. Ivanhoe, Dale Jamieson, Jeff Kasser, Simon Keller, Scott McElreath, Doug McLean, Robert Mabrito, Kelly McShane, Lawrence H. Simon, and two anonymous referees, Susan Armstrong and Wayne Ouderkirk, for helpful comments and discussions, as well as audiences at Boston University's Karbank Symposium on Environmental Philosophy, Colby College's Environmental Studies Colloquium, and Harvard University's Kennedy School of Government, at which earlier versions of this paper were presented.

${ }^{1}$ Throughout this paper I refer to the intrinsic value of "the natural environment" and "nature." Doing so is intended to be a concise way of saying something like "the nonhuman natural world and/or its parts," including nonhuman animals, plants, ecosystems, rock formations, and so on. In order to keep the focus on value theory in this paper, I do not discuss the issue of how, if at all, one should draw the distinction between the natural and the artifactual. Doing so is an important matter, however, and how one resolves it will have a significant impact on what one is saying (or not saying) when attributing intrinsic value to nature.

${ }^{2}$ See, e.g., Andrew Light, "Contemporary Environmental Ethics: From Metaethics to Public Philosophy," Metaphilosophy 33 (2002): 426-49; Bruce Morito, "Intrinsic Value: A Modern Albatross for the Ecological Approach," Environmental Values 12 (2003): 317-36; Bryan G. Norton, "Why I Am Not a Nonanthropocentrist: Callicott and the Failure of Monistic Inherentism,"
} 
intrinsic value is, and the differences among them have made it difficult to judge the success or even the intended target of some of these critics. Nonetheless, the criticisms seem to have been fairly well received among environmental ethicists, and I suspect that those interested in or willing to defend claims about the intrinsic value of nature are rapidly declining in number.

My aim in this paper is to assess these criticisms as they have developed so far and offer a modest defense of the concept of intrinsic value, at least as I understand it. The paper proceeds in three parts. First, I survey the recent critiques and explain what problems the critics have claimed that the concept of intrinsic value brings with it. Next, I consider the various conceptions of intrinsic value invoked by environmental ethicists and outline the differences among them. Finally, I focus in on one of these conceptions and consider how damaging the recent criticisms are to it. Ultimately, I argue that if we think of intrinsic value claims as claims about the ways in which it makes sense for us to care about things, we can understand intrinsic value in such a way that it escapes contemporary criticisms and yet captures a conceptual distinction that, I argue, is indispensable to moral psychology, normative ethics in general, and environmental ethics in particular.

\section{CRITICISMS OF THE CONCEPT OF INTRINSIC VALUE}

There are three main lines of criticism that have been offered recently. First, as Bruce Morito and Anthony Weston have pointed out, the notion that things can possess value independently of the relations they have to other things suggests a peculiarly atomistic picture of the world. ${ }^{3}$ The more we learn about our world, the more we see it as made up of things that are interrelated, interdependent, and defined through their relations with other things. It would be strange, then, to see value as something that can somehow stand alone. It might be thought to be especially strange for those of us who work on environmental issues: we spend much of our time urging people to recognize the interdependence of the different parts of the natural the world. How odd that we should be insisting on values that are independent.

As a way out of this problem, Weston suggests that we replace our old ideas about intrinsic value with a picture that "insists most centrally on the interrelatedness of our values[,] . . . a picture of values dynamically interdepending with other values and with beliefs, choices, and exemplars[,] . . a kind of 'ecology' of values." " In a similar spirit, Morito advocates understanding the

Environmental Ethics 17 (1995): 341-58; and Anthony Weston, "Beyond Intrinsic Value: Pragmatism in Environmental Ethics," in Environmental Pragmatism, ed. Andrew Light and Eric Katz (London: Routledge, 1996), pp. 285-306.

${ }^{3}$ See Morito, "Intrinsic Value: A Modern Albatross" and Weston, "Beyond Intrinsic Value."

${ }^{4}$ Weston, "Beyond Intrinsic Value," p. 285. 
world in terms of "interdepending values as a preparation for a more ecologically coherent approach to environmental protection." 5

The second worry is that believing in intrinsic value would commit us to a metaphysically elaborate (and therefore dubious) picture of the world. Bryan Norton claims that believing in intrinsic value involves believing that value can exist "prior to human conceptualization, prior to any worldview." $6 \mathrm{We}$ might think, along with John Mackie, that such belief posits the existence of a very peculiar property indeed as part of the fabric of the universe. ${ }^{7}$ It is one thing to believe that water existed before conscious beings did; it is quite another to believe that value existed before conscious beings did. Furthermore, given that there is a more straightforward story to be told about how value gets into the world (namely, via valuers), it is not clear that there is good reason to believe that the property of value does inhere in the natural world intrinsically. The main target of this criticism seems to be the views of Holmes Rolston, III, who claims that for nature to be intrinsically valuable it has to be the case that the property of value, which is a natural property just as being made of carbon is a natural property, exists in the world independently of the existence of any conscious minds. On Rolston's view, the world had value in it before we came along, and it will have value in it long after we are gone. ${ }^{8}$

The third worry is that, as many environmental pragmatists have recently

\footnotetext{
${ }^{5}$ Morito, "Intrinsic Value: A Modern Albatross," p. 317.

${ }^{6}$ Bryan G. Norton, Toward Unity among Environmentalists (New York: Oxford University Press, 1991), p. 235. See also Bryan G. Norton, Why Preserve Natural Variety? (Princeton: Princeton University Press, 1987), pp. 180-82; and J. Baird Callicott, "Rolston on Intrinsic Value: A Deconstruction," Environmental Ethics 14 (1992): 129-43. For replies to these criticisms, see Christopher J. Preston, "Epistemology and Intrinsic Values: Norton and Callicott's Critiques of Rolston," Environmental Ethics 20 (1998): 409-28 and Robin Attfield, "Postmodernism, Value and Objectivity," Environmental Values 10 (2001): 145-62. Norton claims that his worry is epistemological, since he believes that intrinsic value claims "cannot be supported by scientific or any other cultural resources - [they] must be supported independently of all experience" (p. 235). This is a puzzling explanation, however. One might well think that water exists in the world in a way that is prior to any human conceptualizations of water, but it does not follow from this that claims about the existence of water here or there must be justified independently of experience.

${ }^{7}$ J. L. Mackie, Ethics: Inventing Right and Wrong (London: Penguin Books, 1977), pp. 38-42.

${ }^{8}$ See, e.g., Holmes Rolston, III, Environmental Ethics (Philadelphia: Temple University Press, 1988), and Holmes Rolston, III, “Are Values in Nature Subjective or Objective?” Environmental Ethics 4 (1982): 125-51. Rolston's view of intrinsic value is very similar in structure to the view of G. E. Moore. The main difference between them is that Moore believes that value is a nonnatural property and Rolston believes that it is a natural property. See G. E. Moore, Principia Ethica, ed. Thomas Baldwin, 2d rev. ed. (Cambridge: Cambridge University Press, 1993). The similarity between these two views has not been lost on commentators - one often finds references to Moore in articles where people run this second line of criticism. In fact, one gets the distinct impression that Moore's view is next in line behind Rolston's on the critics' list of "Bad Ways a Theory Could Turn Out."
} 
been contending, intrinsic value claims also seem to be unnecessary. ${ }^{9}$ We do not need to work up a theory of intrinsic value, they argue, to articulate the importance of the things we hold most dear. Every environmental policy or practical ethical recommendation we would want to defend using intrinsic value claims can be defended equally well using extrinsic value claims. We do not need to show that old-growth forests have intrinsic value to make the case that they should not be destroyed-we can do so just as well by showing the likely effects that destroying them would have on us and the things that we care about. Furthermore, there are good practical reasons for wanting to avoid intrinsic value claims if we can do so. First, as Light argues, the general public is not likely to be moved by claims about so-called intrinsic value in nature; they are much more likely to be moved by claims about contributions that the natural world makes to human well-being. ${ }^{10}$ Second, Norton worries that insisting on intrinsic value claims will make specialists in other fields (e.g., economics) uninterested in what environmental ethicists have to say, since one of the grounding assumptions of these fields is that all value is value-tohumans. This assumption precludes the possibility of intrinsic value, at least in the sense that these philosophers want to use it. ${ }^{11}$ If the concept of intrinsic value is both unnecessary and making life hard for philosophers, then one might think that it is time for this concept to go the way of the mastodon.

\section{KINDS OF INTRINSIC VALUE}

To hear those who would know tell the tale, in the early days of environmental ethics, intrinsic value (and that of nature in particular) was the theoretical

\footnotetext{
${ }^{9}$ See, e.g., Light, "Contemporary Environmental Ethics," Norton, Toward Unity among Environmentalists, and Weston, "Beyond Intrinsic Value." For an opposing view within environmental pragmatism, see Ben A. Minteer, "Intrinsic Value for Pragmatists?" Environmental Ethics 22 (2001): $57-75$.

${ }^{10}$ Light, "Contemporary Environmental Ethics," p. 427.

${ }^{11}$ See Norton, "Why I Am Not a Nonanthropocentrist," pp. 343-44, and Bryan G. Norton, "Integration or Reduction: Two Approaches to Environmental Values," in Environmental Pragmatism, ed. Andrew Light and Eric Katz (London: Routledge, 1996), p. 121. The field of environmental economics has tried overcome some of these problems in a different way, at least with respect to the gap between ethics and economics. In response to some of the claims made by environmentalists and environmental ethicists about nature's value, environmental economists have come up with different kinds of value that try to capture some nonanthropocentric intuitions. So they have introduced concepts such as existence value, bequest value, and even an economistsanctioned version of the concept of intrinsic value. But I think that the results of these attempts have been decidedly mixed, at least so far. There is still widespread disagreement even among environmental economists about how to understand these concepts and whether to accept them at all. It is also not clear that these concepts can capture the intuitions they were meant to capture. See, e.g., Jonathan Aldred, "Existence Value, Welfare and Altruism," Environmental Values 3 (1994): 381-401, and Mark Sagoff, "Existence Value and Intrinsic Value," Ecological Economics 24 (1998): 163-68.
} 
holy grail. ${ }^{12}$ Everybody wanted to find a theory on which it would turn out that nature had intrinsic value - in fact, some claimed that to be an environmental ethic at all, a theory had to be able to attribute intrinsic value to nature. ${ }^{13}$ However, the use of the term intrinsic value in environmental ethics at that time was a lot like the use of the term freedom these days in American political discourse. It was used to designate something that everybody is in favor of, even though (and perhaps because) nobody is really sure what they mean by it. In environmental ethics, the term intrinsic value was used to refer to a number of very different ethical concepts. We can group them into roughly four categories:

(1) Views according to which claims about the intrinsic value of $X$ are claims about the distinctive role that $X$ should play in moral decision making.

(2) Views according to which claims about the intrinsic value of $X$ are claims about the distinctive way that it makes sense to care about $X$.

(3) Views according to which claims about the intrinsic value of $X$ are claims about which properties of $X$ make it valuable.

(4) Views according to which claims about the intrinsic value of $X$ are claims about the metaphysical status of $X$ 's value properties.

Views of intrinsic value in the first group usually involve the claim that intrinsically valuable things are supposed to have a special kind of importance in moral decision making that other things do not have. According to some of these views, intrinsically valuable things are those that have moral standing - i.e., they are such that we must consider their interests when thinking about doing something that might affect them. ${ }^{14}$ According to others, intrinsically valuable things are independent sources of moral duties - i.e., they are such that we have duties to them, not just duties that somehow involve them. ${ }^{15}$ Still others involve the claim that intrinsic values are the kind of values that should outweigh, trump, or even silence other values in cases of conflict. ${ }^{16}$

\footnotetext{
${ }^{12}$ Norton, "Why I Am Not a Nonanthropocentrist," p. 343. See also Morito, "Intrinsic Value: A Modern Albatross."

${ }^{13}$ See, e.g., Tom Regan, "The Nature and Possibility of an Environmental Ethic," Environmental Ethics 3 (1981): 19-20, and J. Baird Callicott, "Intrinsic Value in Nature: A Metaethical Analysis," in Beyond the Land Ethic: More Essays in Environmental Philosophy (Albany: State Universiy of New York Press, 1999), p. 241. Michael Soulé makes a similar point about the relationship of intrinsic value claims to conservation biology. See Michael E. Soulé, "What Is Conservation Biology?" BioScience 35 (1985): 731-32.

${ }^{14}$ See, e.g., Paul Taylor, Respect for Nature: A Theory of Environmental Ethics (Princeton: Princeton University Press, 1980).

${ }^{15}$ See, e.g., Tom Regan, The Case for Animal Rights (Berkeley: University of California Press, 1983), pp. 193-31.

${ }^{16}$ See, e.g., Karl F. Nordstrom, "Intrinsic Value and Landscape Evaluation," Geographical Review 83 (1993): 473-76.
} 
Views of intrinsic value that fall into the second group are concerned with the different ways that we value things. They tend to contrast valuing things intrinsically, on the one hand, with valuing things instrumentally, as a means, or for the sake of some other thing, on the other hand. One most often sees the claim that to value something intrinsically is to value it for its own sake, and thus that for a thing to be intrinsically valuable is for it to be properly or appropriately valued for its own sake. ${ }^{17}$

Views that fall into the third group tend to involve the claim that for a thing to be intrinsically valuable is for it to be valuable in virtue of its intrinsic properties. Intrinsic properties are then understood as nonrelational properties, or perhaps more correctly "non-externally relational" properties. ${ }^{18}$ Thus, for an object to be intrinsically valuable is for it to be valuable in virtue of properties that aren't a matter of relating it to something outside of itself. One also occasionally finds views in this third group involving the claim that for something to be intrinsically valuable is for it to be valuable in virtue of its essential nature-i.e., in virtue of its essential properties. ${ }^{19}$ It is not clear why one would want to call this kind of value intrinsic value rather than essential value, for not all essential properties are intrinsic properties. ${ }^{20}$ But, in any case, people do call the value of a thing that is valuable in virtue of its essential nature a kind of intrinsic value, and this is another view of the third type. ${ }^{21}$

Views that fall into the fourth group are views about the metaphysical status of a thing's value, and they can get fairly complex in their details. But roughly the idea is this: one of the things that we might be asking when we ask whether something has value in its own right is whether it would still have this value even if we were not around, even if no valuers were around, and/or even if it was the only thing that existed in the universe. If it would still have value under

\footnotetext{
${ }^{17}$ See, e.g., Michael Lockwood, "End Value, Evaluation, and Natural Systems," Environmental Ethics 18 (1996): 265-78.

${ }^{18}$ For example, an intrinsic property of my left shoe is having a rubber sole; an extrinsic (i.e., externally relational) property of my left shoe is being to the left of my right shoe.

${ }^{19}$ Essential properties are those that make a thing what it is. For example, four-sidedness would be an essential property of a square. If a figure did not have this property, it would not be a square.

${ }^{20} \mathrm{Here}$ is an example of an essential property that is not an intrinsic property: it is a property that I possess, namely, having my particular biological parents. This is clearly a relation I have to something outside of myself, namely, to my parents, but it is also a property that makes me the thing that I am. If I did not have this property - that is to say, if I did not have my particular biological parents - I would not be me.

${ }^{21}$ An example of this type of view is Christine Korsgaard's. See Christine M. Korsgaard, "Two Distinctions in Goodness," in Creating the Kingdom of Ends (Cambridge: Cambridge University Press, 1996), 249-74. She describes intrinsic value as unconditional value, but it is essential properties rather than intrinsic properties that are possessed by things unconditionally-i.e., in every possible world. For a further discussion of this point, see Wlodek Rabinowicz and Toni Rønnow-Rasmussen, "A Distinction in Value: Intrinsic and for Its Own Sake," Proceedings of the Aristotelian Society 100 (2000): 33-51.
} 
these circumstances, then its value must be intrinsic - i.e., its value must inhere in the thing itself rather than in a relation between the thing and something else. This way of thinking about how we should understand the intrinsicness of intrinsic value is part of the philosophical legacy of G. E. Moore - it is Moore's isolation test. ${ }^{22}$ The views that fall into this fourth group can be seen as attempts to square the talk of intrinsic value in ethics with the talk of intrinsic properties in metaphysics. They allow us to say that being valuable is a property of objects in a way similar to the way in which being made of carbon is a property of objects. They are both properties that do not depend on a relation that the object bears to something outside of itself, and thus they are both properties that the object would retain if everything outside of itself disappeared.

Of course, to categorize views into these four groups is not to say that a view cannot fall into more than one of them. Holmes Rolston's view of intrinsic value described earlier falls into groups (3) and (4); Tom Regan's view of inherent value falls into both (1) and (2); and so on. While relations between the groups certainly are not ones of logical entailment, it is true that adopting claims within one group can, especially in the presence of other theoretical elements, make claims within one or more of the other groups look very attractive.

\section{AN ACCOUNT OF INTRINSIC VALUE}

Although there is quite a bit to say about how the three criticisms mentioned above apply to each of these four versions of intrinsic value, that would require much more room than is available here. Instead, I intend to focus on the second version, the view that claims about a thing's intrinsic value are claims about how it makes sense for us to care about the thing. I think that this issue is really at the core of environmental ethicists' interest in intrinsic value. That is to say, I suspect that it is really an interest in accounting for nature's intrinsic value in this second sense that has led theorists to posit its intrinsic value in the other three senses. I discuss this point further below. First, however, let me do what I can to motivate two claims: (1) that we have good reason to want intrinsic value of this type in our conceptual repertoire, and (2) that it can make sense to attribute intrinsic value of this type to at least some parts of the natural world. In order to motivate these claims, it is useful first to get a rough idea of what an account of intrinsic value in this second sense might look like.

Let us take a step back for a moment and think about what value really is. Our attributions of value are closely tied to our practices of valuing. When we say that $X$ is valuable, part of what we are saying is that $X$ is the sort of thing that it makes sense to value. More precisely, we are saying that $X$ merits or deserves

${ }^{22}$ See Moore, Principia Ethica, pp. 142-47, 236-38. 
to be valued by valuers. ${ }^{23}$ This understanding of value is not new. An analysis of this type was defended by Franz Brentano and more recently by Elizabeth Anderson. ${ }^{24}$ It does, however, seem to be currently experiencing a resurgence in popularity. ${ }^{25}$

Of course, as many of the sentimentalists have pointed out, we rarely if ever just plain value things. Rather, we take some particular valuing attitude toward them-admiration, awe, respect, and so on. Corresponding to these particular valuing attitudes are particular kinds of value: admirability, awesomeness, respectworthiness, etc. To say that $X$ is valuable, then, is to say that $X$ merits or deserves one or more of these particular valuing attitudes. ${ }^{26}$

Among these particular valuing attitudes, some have a different structure than others. Some are what we might call intrinsic valuing attitudes - ways of valuing something for its own sake, or in its own right, while others are what we might call extrinsic valuing attitudes - ways of valuing something for the sake of some other valuable thing. Some philosophers have wanted to use the language of means and ends to describe this distinction, referring to intrinsic valuing attitudes as ways of valuing things as ends and extrinsic valuing attitudes as ways of valuing things as means. However, this language has caused a tremendous amount of confusion in the literature, particularly in the

${ }^{23}$ Here is the reason that the latter formulation is more precise: suppose we define being admirable just as "being the sort of thing it makes sense to admire." The problem is that it can make sense to admire things for all sorts of reasons, some of which have nothing to do with the features that make a thing admirable. Suppose, for example, that my boss is particularly sensitive to the opinions that her employees have of her, and she systematically rewards those who admire her and fires those who do not. Suppose that I love my job, cannot find another, my boss is very good at detecting genuine admiration, and I am very bad at faking admiration. There is a very real sense in which she is someone it does make sense for me to admire - that is, if I know what is good for me-but this fact hardly makes her admirable. Circumstances can sometimes give us reasons to admire those who are not really admirable. But if we were to define admirability in terms of what it makes sense to admire, then my boss would meet this condition, and so she would turn out on this definition to be admirable. This is what has been referred to in the philosophical literature as the "Wrong Kind of Reasons Problem." For a discussion, see Justin D'Arms and Daniel Jacobson, "Sentiment and Value," Ethics 110 (2000): 722-48, and Wlodek Rabinowicz and Toni Rønnow-Rasmussen, “The Strike of the Demon: On Fitting Pro-Attitudes and Value," Ethics 114 (2004): 391-423; Wlodek Rabinowicz and Toni Rønnow-Rasmussen, "Buck-Passing and the Right Kind of Reasons," Philosophical Quarterly 56 (2006): 114-20; Jonas Olson, "BuckPassing and the Wrong Kind of Reasons," Philosophical Quarterly 54 (2004): 295-300; and Philip Stratton-Lake, "How to Deal with Evil Demons: Comment on Rabinowicz and RønnowRasmussen," Ethics 115 (2005): 788-98.

${ }^{24}$ Franz Brentano, The Origin of Our Knowledge of Right and Wrong, trans. Roderick Chisholm and Elizabeth Schneewind (London: Routledge and Kegan Paul, 1969); Elizabeth Anderson, Value in Ethics and Economics (Cambridge: Harvard University Press, 1993). See also Gerald F. Gaus, Value and Justification: The Foundations of Liberal Theory (Cambridge: Cambridge University Press, 1990).

25 See, e.g., D’Arms and Jacobson, "Sentiment and Value," and Rabinowicz and RønnowRasmussen, "The Strike of the Demon."

${ }^{26}$ Elizabeth Anderson argues for a pluralism of just this type. See Anderson, Value in Ethics and Economics, chap. 1. 
environmental ethics literature, in part because people tend to conflate two very different meanings of means and ends.

The first sense of means and ends comes from everyday speech, where we use the term end to denote a goal or an aim, and we use the term means to denote that which one uses to achieve a goal or an aim. When we say that something is a means to an end in this sense, we are claiming that it is useful for achieving a goal or an aim. Since, metaphysically speaking, a goal or an aim must be a state of affairs rather than, e.g., a concrete particular such as a person, only states of affairs can be ends in this first sense. (For example, I cannot take you as my goal, though I can take states of affairs involving you as my goal-e.g., that you exist or that you be happy). Thus, persons, trees, and other concrete particulars cannot be ends in this first sense. Means will not be as metaphysically limited, but the relation between means and ends will have to be a causal or at least potentially causal one, for to say that a means is used to achieve an end implies that the means is somehow causally efficacious in bringing about the end. ${ }^{27}$ This first sense of means and ends has its natural home in discussions of deliberate actions - cases where we do or use something in order to achieve something else. It is this first sense of means and ends that we have in mind when we say such things as "The end justifies the means."

In the second sense, end is used to describe something that has value in its own right (nonderivative value), and means is used to describe something that has value in virtue of a relation it has to some end (derivative value). ${ }^{28}$ Understood in this second sense, an end could be a state of affairs, a concrete particular, an abstract object, a universal - whatever kind of thing it is that one thinks has value in its own right. A means will be anything that has value because of its relation to an end. Furthermore, unlike the case with the first sense, this relation need not be a causal one-it might be, for example, representational or symbolic. Thus, something like a memento would count as a means in this second sense but not in the first sense. A memento has value not because of what it does - not because it is used to achieve any goal or aim - but because of what it signifies or represents. ${ }^{29}$ This second sense of means and ends is applicable even in cases where one is not acting in the pursuit of a goal. It is this sense of ends and means that is involved in Kant's claim that we should never treat humanity as a mere means, but always as an end in itself. ${ }^{30}$

These two senses have frequently been confused with each other, and

${ }^{27}$ See Thomas Carson, "Happiness and the Good Life," Southwest Journal of Philosophy 9 (1978): 75.

${ }^{28}$ Cf. Dale Jamieson, "Values in Nature," in Morality's Progress (Oxford: Oxford University Press, 2002), pp. 225-43. The way I am using the term derivative here is different from the way that Jamieson uses it.

${ }^{29}$ This example is from Anderson, Value in Ethics and Economics, p. 3.

${ }^{30}$ Immanuel Kant, Groundwork of the Metaphysics of Morals, in Practical Philosophy, ed. Mary J. Gregor, The Cambridge Edition of the Works of Immanuel Kant (Cambridge: Cambridge University Press, 1996), pp. 39-108. 
features of one have been incorrectly taken to apply to the other. For example, some environmental ethicists have assumed that all derivative value (second sense) must be instrumental value (first sense), argued that the value of nonhuman nature goes beyond its mere usefulness for achieving our ends (first sense), and concluded that nature's value must be nonderivative (second sense). ${ }^{31}$ Others have assumed that to be derivatively valuable (second sense) a thing must have some causal connection to our goals or aims (first sense), and for this reason they have worried about whether a thing can have any value at all if there is nothing it can do for us. ${ }^{32}$ Although philosophers have made some progress recently in sorting out these confusions, there is still more work to be done. ${ }^{33}$ For this reason, I think it is better to avoid talk of means and ends entirely.

An example of an attitude that I think, at least in many of its forms, is an intrinsically valuing attitude is the attitude of love. Part of what it is to love something is to value it as a good in itself. ${ }^{34}$ If I say that I love you, but then claim that your only value is that you remind me of somebody else, you will probably be skeptical that what I'm feeling for you is really love. Your skepticism is understandable, for loving something is a way of valuing that thing in its own right. Love involves seeing the object of love as having worth independently of the value of other things that you (and others) care about. Another way of putting this point is to say that the source of value is the loved thing, rather than, for example, our relationship with it, the way it makes us feel, the states of affairs that include it, etc. To love something is to make it a primary object of your concern. If I genuinely love you, what I value is you, not the joy you bring to my life, the person you inspire me to be, the experience of friendship you

${ }^{31}$ See, e.g., J. Baird Callicott, "Non-Anthropocentric Value Theory and Environmental Ethics," American Philosophical Quarterly 21 (1984): 299-309, and Joseph R. Des Jardins, Environmental Ethics: An Introduction to Environmental Philosophy, 2d ed. (Belmont, Calif.: Wadsworth Publishing Co., 1997), pp. 127-30. For slightly different criticisms of this type of reasoning, see John O'Neill, “The Varieties of Intrinsic Value," The Monist 75 (1992): 119-37, and Karen Green, "Two Distinctions in Environmental Goodness," Environmental Values 5 (1996): 31-46.

${ }^{32}$ See, e.g., Bryan G. Norton, "Environmental Ethics and Weak Anthropocentrism," Environmental Ethics 6 (1984): 131-48.

${ }^{33}$ For examples of the progress, see Korsgaard, "Two Distinctions in Goodness," and Shelly Kagan, "Rethinking Intrinsic Value," Journal of Ethics 2 (1992): 277-97. For a description of some of the work still to be done, see Rabinowicz and Rønnow-Rasmussen, "A Distinction in Value."

${ }^{34}$ Cf. J. David Velleman, “Love as a Moral Emotion," Ethics 109 (1999): 338-74. Of course, the English word love probably refers to a number of different attitudes. The sense in which I love my parents, the Red Sox, or true crime stories might all be quite different. The remarks about love here should be taken to be limited to the kind of love one feels for friends, family, or romantic partners. It is this kind of love that is a form of intrinsic valuation, and it is this kind that environmentalists think people can, do, and should take toward parts of the natural environment. Thanks to Simon Keller for urging the importance of this point. 
allow me to have, etc. To be sure, I probably value these things too; loving relationships often bring with them many benefits. But these values are secondary - they do not constitute the love, but are rather added to it.

All this is to say that love has a certain structure, a structure that looks an awful lot like intrinsic valuation. But love is not the only attitude that works this way. Respect, and (at least in some manifestations) reverence and awe also seem to have a similar structure. To respect something is in part to treat it as having a kind of importance in its own right; to be in awe of something is in part to treat it as having a kind of greatness in its own right, to revere something is in part to treat it as having a kind of dignity or nobility in its own right. One reason that we might find the concept of intrinsic value useful, then, is that we seem to do a lot of intrinsic valuing. ${ }^{35}$

But it is not just that we happen to value some things intrinsically and other things extrinsically - this is not merely an interesting little fact about human psychology. (After all, you might think, there are many quirks about human psychology of which ethics does not need to take account.) On the contrary, the distinction between intrinsic and extrinsic valuation plays an important role in ethics, and rightly so. We think that some things should be valued intrinsically and other things should be valued extrinsically. While these judgments will usually be context dependent, they are nonetheless very important in our thinking about what to do and how to feel. For an example, consider the case of Ebeneezer Scrooge, the character from Charles Dickens' A Christmas Carol. ${ }^{36}$ What was Scrooge's moral mistake? His mistake was that he valued money intrinsically and he valued people extrinsically (instrumentally, in fact). ${ }^{37}$ He got it backwards. People are supposed to be valued intrinsically and money is supposed to be valued extrinsically. In fact, that is the whole point of the morality tale - and it has a happy ending because Scrooge finally figures out his mistake and gets it right. But Scrooge is not that uncommon: many of our morality tales are about people who care about the wrong things in the wrong ways and how they do or do not fix this mistake.

On this picture, what would we lose if we were to give up on the idea of intrinsic value? If we were to agree with those who say that nothing could have intrinsic value, then none of these kinds of intrinsic valuation could be warranted in the sense that none of them could be merited by their objects. If loving something involves thinking of it as having value in its own right, then if nothing does have value in its own right, loving things would involve a kind

\footnotetext{
35 See Minteer, "Intrinsic Value for Pragmatists?" for a similar claim.

${ }^{36}$ See Charles Dickens, A Christmas Carol (Peterborough, Ontario: Broadview Press, 2003).

${ }^{37}$ That Scrooge is unfriendly and a miser is well known, but the text also provides glimpses of his attitudes toward human relationships in general:"'Why did you get married?' said Scrooge. 'Because I fell in love.' 'Because you fell in love!' growled Scrooge, as if that were the only thing in the world more ridiculous than a merry Christmas" (ibid., p. 43).
} 
of mistake. ${ }^{38}$ It would be like believing propositions we know to be false: we would be thinking of the object as having a kind of value that we know it does not really have. What we lose, then, in giving up the concept of intrinsic value, is the prospect of an ethics that can accept the structure of many of our most common valuing attitudes, rather than treating them as mere mistakes.

In fact, I would argue that it is this connection between the kind of value people think something has and attitudes they think it makes sense to take toward it that largely explains the interest in the concept of intrinsic value from environmental ethicists. The idea, I think, is this: we can, do, and should take some of the same intrinsically valuing attitudes toward things in the nonhuman natural world that we do toward things in the human world. We can, do, and should at least sometimes think of some parts of the natural world as appropriate objects of awe, reverence, respect, and love. We should not reserve this role in our emotional lives for humans alone.

In reading through the environmentalist literature (not the environmental ethics literature, but something more like what bookstores call "nature writing"), one sees writers making this claim over and over again. Aldo Leopold tells his readers that he is in love with pine trees, and he argues that people need to learn how to feel "love, respect and admiration for the land." 39 Willa Cather also speaks of love that people have for the land. ${ }^{40}$ David James Duncan explains how he fell "heart over head in love" with the Blackfoot River, and then describes the grieving process he went through after deforestation of surrounding areas filled it with silt, destroying much of the ecosystem. ${ }^{41}$ John Fowles and John Muir compare the awe, wonder, and reverence that nature inspires to that which cathedrals and temples are meant to inspire. Fowles even goes so far as to claim, ". . . I am certain that all sacred buildings, from the greatest cathedral to the smallest chapel, and in all religions, derive from the natural aura of certain woodland or forest settings. In them we stand among older, larger, and infinitely other beings, remoter from us than the most bizarre other nonhuman forms of life: blind, immobile, speechless . . , waiting. . ." "42 The list goes on and on. Edward Hoagland, Carl Pope, Barry Lopez, Rachel Carson,

\footnotetext{
${ }^{38}$ It would not involve a mistake from the perspective of prudence or from the perspective of what one has reason to do generally. After all, one might have a prudential interest in loving things, and prudential reasons are relevant to what one should or should not do. Rather, it would involve a mistake from the perspective of value, where the question is not how one should behave generally but what behavior is merited by the object of valuation. Reasons seen from the perspective of value are reasons for action/attitude, but they are only prima facie reasons and not even the only kind of those.

${ }^{39}$ Aldo Leopold, A Sand County Almanac with Essays on Conservation from Round River (New York: Ballantine Books, 1970), pp. 74, 261.

${ }^{40}$ See, e.g., Willa Cather, O Pioneers! (Oxford: Oxford University Press, 1999), pp. 39, 169.

${ }^{41}$ David James Duncan, “The War for Norman's River," Sierra 83, no. 3 (1998): 49.

${ }^{42}$ John Fowles, The Tree (New York: Ecco Press, 1983), p. 58. See also John Muir, My First Summer in the Sierra (New York: Penguin Books, 1987), p. 49.
} 
Wallace Stegner, and many others all describe various intrinsic valuing attitudes that they take toward parts of the natural environment and urge these attitudes upon their readers.

That these attitudes are important for the purposes of ethics is also made clear. Leopold claims, "That land is a community is the basic concept of ecology, but that land is to be loved and respected is an extension of ethics." 43 Notice that he does not say "that the land is to be preserved" or "that the land is to be managed wisely" - he says that the land is to be loved and respected. This same sentiment is behind Dale Jamieson's claim that "the environmental problems that we face today are not fundamentally scientific problems. In large part the environmental crisis is a crisis of the human heart." 44

In fact, part of what I think many environmentalists find offensive about purely economic assessments of the value of nature is that even if they give us the right answer about how much to value the natural world, they give us the wrong answer about how to value the natural world. ${ }^{45}$ The fact is, we care about economic goods in particular ways, and those ways of caring are not appropriate for every other thing about which we care. If you were to ask me how much the friendships I have are worth to me in dollar terms - for example, by asking how much I would pay to keep a friendship, or how much you would have to pay me to be willing to give up a friendship - I would have no answer for you, not because my friendships have infinite value to me or because they have no value at all, but rather because you are asking me to extend an economic mode of valuation to an area where it is not appropriate.

There is, of course, a slight disanalogy here, for I do not think environmentalists object to all economic assessments of environmental value in the way that I would with the value of my friends. They just object to the claim that this is the only mode of valuation that is appropriate to the natural world. Furthermore, to stick up for economists a bit here, I do not know of any economists who claim that economic modes of valuation are the only legitimate modes of valuation. ${ }^{46}$ If policy makers only solicit assessments from economists, and if economists' particular specialty is coming up with economic assessments, then it is not the economists' fault if nature's value only gets assessed in economic terms. It is the policy makers' fault for only asking for economic assessments, and it is our fault - both for not finding ways to be more articulate about these

\footnotetext{
${ }^{43}$ Leopold, A Sand County Almanac with Essays on Conservation from Round River, p. xix.

${ }^{44}$ Dale Jamieson, "Ecosystem Health: Some Preventive Medicine," Environmental Values 4 (1995): 342.

${ }^{45}$ See Mark Sagoff, "Zuckerman's Dilemma: A Plea for Environmental Ethics," Hastings Center Report 21 (1991): 32-40, and Jamieson, "Values in Nature," pp. 237-38, for similar claims.

${ }^{46}$ Although, as Dale Jamieson has pointed out (in personal correspondence), "many economists are quite skeptical about the sorts of non-quantifiable values [described above] and many more would say that such values, if they exist, are like religious values and should not be taken into account when making public policy."
} 
other kinds of value that we think nature has, and for not demanding that our policy makers include these sorts of values in their decision-making processes.

It is worth noting that what I described above is a very pluralistic theory of value. It recognizes that there are different kinds of value, not just different amounts of value, and among those different kinds are intrinsic and extrinsic value. But it also offers us a pluralistic conception of intrinsic value, for there are different kinds of that as well. Something could be intrinsically valuable in virtue of being awesome, or in virtue of being loveable, or in virtue of meriting any intrinsically valuing attitude. To know that something is intrinsically valuable, on this type of view, is not really to know all that much. We need to know in what way it is intrinsically valuable.

This pluralism makes good sense, for the way it is appropriate to treat the proper objects of different kinds of intrinsic valuation are quite different. Consider the difference between the ways that it is appropriate to treat the proper objects of awe, on the one hand, and the proper objects of love, on the other hand. You might want to say that both the Mona Lisa and your daughter have intrinsic value, the artwork because it is the appropriate object of awe and the child because she is the appropriate object of love. But the ways that it is appropriate to treat them will be quite different. It might be appropriate to put the Mona Lisa in a big plastic cage to protect it from flashbulbs and treat it with various chemicals in order to ensure that it changes as little as possible over time. But to lock your daughter away and carefully control the environment in an attempt to prevent her from changing in any way would be terrible. You should nurture her, help her to develop and change over time, and try to make it so that she changes in good ways rather than bad ones. But taking this strategy of benevolent improvement with the Mona Lisa would be a disaster. The Mona Lisa probably would look better in a nice hat, but you should not add one, even if the hat would constitute an aesthetic improvement.

To conclude this section, then, I think that in order to have an adequate moral psychology, we need to be able to account for the difference between valuing things intrinsically and valuing them extrinsically. In order to have an adequate ethical theory, we need to be able to say something about when these ways of valuing are or are not appropriate. That is to say, we need to be able to distinguish between intrinsic and extrinsic value. If we were to give up the concept of intrinsic value, we would have no way to make such a distinction.

\section{CRITICISMS REVISITED}

But what about the objections mentioned earlier? Let us consider how each of them may or may not apply to the version of intrinsic value I have just described. First, consider the worry about atomism. Morito claims, "'Intrinsic value' is ... a concept born in the Western intellectual tradition for purposes of insulating and isolating those to whom intrinsic value can be attributed from 
one another and their environmental context." 47 Weston claims that instead of thinking that the world could contain individual bearers of intrinsic value, we should prefer "an understanding of values themselves as dynamically interdependent systems such that we could almost speak of an 'ecology' of value."48 I think we need to distinguish between strong and weak versions of the worry that has been articulated here. On the strong version, it is a problem if a theory individuates things at all. Of course, while it is true that some deep ecologists seem to make this claim (for example, Warwick Fox has said that "to the extent that we perceive boundaries, we fall short of deep ecological consciousness"49), I think this view is a nonstarter. For whatever reason, our cognitive apparatus is such that we do individuate objects in our world - we think of the world as containing separate things, even as we notice all of the relations among these things. In fact, as any expert in childhood development can attest, individuation of objects in the world is one of the first tasks that our minds begin to perform-well before we acquire language. ${ }^{50}$ Even for the critics' theoretical purposes we would have to individuate things, for in order to have relations at all there must be relata (the things that are related by the relations). It does not make sense to talk about relations unless we can acknowledge that there are things being related. Our attitudes toward and ways of caring about the world, as well as our ethical relationships, also often require us to separate out individual things from the rest of the mass of stuff we encounter. I have to understand myself as separate from you in order to love or hate you; I need to know which parts of the world you refers to in order to resent you or feel guilty about how I treated you. I also need to individuate the you parts of the world in order to think that I have ethical obligations toward you. The kinds of conceptual separations required by these modes of thinking are not contrary to an "ecological world view" that notices and values systems, processes, and relationships. Rather, this is the type of thinking needed to make sense of these systems, processes, and relationships - that there are things that make up systems, go through processes, and enter into relationships with other things. To allow this much is not to adopt an atomistic view of the world-or if it is, then atomism is not always a bad thing.

But there is a weaker version of this worry, which is where I think this first criticism really has its force. It is not that every form of individuation is bad,

\footnotetext{
${ }^{47}$ Morito, "Intrinsic Value: A Modern Albatross," p. 317.

${ }^{48}$ Anthony Weston, "Unfair to Swamps: A Reply to Katz," in Environmental Pragmatism, ed. Andrew Light and Eric Katz (London: Routledge, 1996), p. 319.

${ }^{49}$ Warwick Fox, "Deep Ecology: A New Philosophy of Our Time?" The Ecologist 14 (1984): 201-04, quoted in Bill Devall and George Sessions, Deep Ecology: Living as if Nature Mattered (Salt Lake City, Utah: Gibbs Smith, 1985), p. 66.

50 See, e.g., David H. Rakison and Lisa M. Oakes, eds., Early Category and Concept Development: Making Sense of the Blooming, Buzzing Confusion (Oxford: Oxford University Press, 2003).
} 
the critic might argue, but rather that a theory that tells us to understand the world by dividing it up into individuals and then looking at the properties of these individuals will tend to miss the importance of relations, systems, processes, etc. It could miss them because the theory makes individuation and analysis the only mode of understanding phenomena, or it could do so because the theory makes individuation and analysis the primary mode of understanding phenomena. In any case, the worry is that by emphasizing the role of the individual in our understanding of the world, we will tend to miss the importance of these other things. ${ }^{51}$

In ethics and political philosophy, versions of this sort of criticism have been around for a long time. For example, many have criticized ethical views that try to decide moral questions simply by looking at who has a right to what. ${ }^{52}$ The worry is that when we make moral decisions in this manner, we tend to ignore many other morally important aspects of the situations we face. (If you doubt whether this is true, just look at some of the bizarre arguments that come out of the U.S. legal system, where many decisions do have to get made this way.)

However, this criticism only has force against the view I have just described to the extent that this view is telling us to treat intrinsic value as though it were the most important or perhaps the only important kind of value. But nothing in the view says that, and for good reason. Not even the strongest supporters of intrinsic value think it is the only kind of value there is. ${ }^{53}$ There are also all sorts of extrinsic values, and in any given case the extrinsic considerations might turn out to be a lot more important than the intrinsic ones. To borrow an example of Jamieson's, you might rightly value the thread by which you are hanging thousands of feet above a river a lot more than you value your stamp collection, even though you value the former extrinsically and the latter intrinsically. ${ }^{54}$ This example might strike some opponents of intrinsic value as odd, but the reason it is true is that intrinsic value does not mean absolute value. There is nothing about the concept of intrinsic value as described above that says intrinsic values are always more important than extrinsic values, or that they can never be outweighed by other considerations, or that possessing intrinsic value makes a thing inviolable. In order to make these claims, we would have to join the view just laid out with some view from the first group

\footnotetext{
${ }^{51}$ This seems to be Norton's reasoning - see Bryan G. Norton, Sustainability: A Philosophy of Adaptive Ecosystem Management (Chicago: University of Chicago Press, 2005), p. 183.

${ }^{52}$ See, e.g., Onora O'Neill, “Children's Rights and Children's Lives,” Ethics 98 (1988): 44563.

${ }^{53}$ Technically, one exception to this view might be found among those who claim that to be extrinsically valuable is not really to have a kind of value, but rather to be instrumental in producing value. But this is only technically an exception, for such people think that there is good reason to care quite a bit about these instruments. Thus, the fact that extrinsic value is not really a kind of value on this view does not mean that one should not care about it.

${ }^{54}$ Jamieson, "Values in Nature," p. 236.
} 
(that is to say, a view about the role that intrinsically valuable things should play in our moral decision making), and with a particularly simple-minded view at that.

Once we give up the idea that believing in intrinsic value means holding some sort of hyper-atomistic picture of the world on which the only thing that matters for the purposes of ethics is what each individual thing is like in its own right, there is less reason to be disturbed by the claim that our deeply interconnected world contains things that deserve to be intrinsically valued. Nothing in our world exists in isolation and there is no reason that we should want to think of things just as isolated individuals for the purposes of ethics. We might well agree that extrinsic values have been underappreciated and that the ultimate value of things will always depend on their relationships to other things. But we can do so while insisting that some things are worth caring about in their own right.

Weston, Morito, and Norton are right that we need to do a much better job than we have done, particularly in environmental ethics, of describing extrinsic values - not only the extent and the rich variety of such values, but also their importance for many of the moral decisions that we need to make. But the way to solve this problem is not to give up on the idea of intrinsic value altogether. If there is a problem of emphasis, then we should change our emphasis. But to give up on the idea of intrinsic value entirely would only generate a new set of problems.

As for the second criticism, the view just described avoids the dubious metaphysical claims about which Norton and others are worried, perhaps because it does not take a stand on the metaphysical status of ethical norms at all. There is nothing about intrinsic value of this second type that commits us to taking any position, much less a wildly implausible position, on these matters. If for something to have value is for it to be such that it merits certain sorts of treatment - both attitudes and actions - from valuers, then it is an open question whether anything could have value in a world where there were no valuers. We might want to say no-for how could an object merit a certain kind of treatment from beings that do not exist? Or we might want to say yes - claiming that all this would mean is that should any valuers come along, they would have reason to treat the object in this way. But which way we would go on this matter is an open question - there is nothing about things meriting intrinsic valuation that commits us to going either way. ${ }^{55}$

The response to the third criticism is probably clear by this point. Even if it

\footnotetext{
55 This second criticism, I think, really applies better to views within the fourth group - views on which claims about intrinsic value are claims about the metaphysical status of value. Rolston's view in particular seems to invite such worries. But the rest of us need not mean what Rolston means by intrinsic value. If we do not, our conception of intrinsic value need not be subject to the metaphysical worry.
} 
were true that considerations of extrinsic value could justify the same policies as considerations of intrinsic value, they still would not be able to justify taking the same attitudes. That is to say, they would not say that it makes sense to care about things in the same way. But, of course, ethics is not just a matter of figuring out which public policies we ought to adopt, and so getting the right answer on that score is not the only task of a theory. ${ }^{56} \mathrm{We}$ want theories that can help us make sense of the world in more ways than this - we want theories that can help us figure out how to think and feel about the different parts of the world in which we live. Even if they would recommend the same policy choices, then, if the two theories endorse different attitudes - if, for example, one says it is appropriate to love the Rocky Mountains and the other says it is a kind of mistake to do so - this is a difference about which we still have reason to care.

Some environmental pragmatists have seen this worry and have argued that even if nature is only valuable insofar as it serves our needs, we can still say that people ought to value nature intrinsically. ${ }^{57}$ Why? Because valuing nature intrinsically is good for us - doing so meets a deep-rooted human psychological need. So the claim is that the act of intrinsically valuing nature has extrinsic value. We should intrinsically value nature because it benefits us to do so.

I think, however, that this reply will not work. It is one thing to say that you ought to be in awe of something because it is great in some way that makes this response of yours appropriate - i.e., because it has whatever properties qualify a thing as being an appropriate object of awe ${ }^{58}$ But it is another thing to say that you ought to be in awe of something because I will give you five dollars if you can do it. To say the first is to make a straightforward value claim - a claim about which objects in the world merit which attitudes from valuers. But to say the second is to ask you to engage in an act of self-deception, or at least hypocrisy, though one that will make you better off. It says that you should adopt the attitude of awe toward something even though it clearly does not merit that awe. ${ }^{59}$ That is to say, it asks you to value something that is not

\footnotetext{
${ }^{56} \mathrm{Cf}$. Norton, Sustainability, p. 151: "Because our approach is practical, the contexts sought for learning about theory and testing various linguistic formulations is to be sought in the trenches' of policy and management. ..."

${ }^{57}$ See, e.g., Norton, "Environmental Ethics and Weak Anthropocentrism." Ben Minteer ("Intrinsic Value for Pragmatists?") argues along similar lines, claiming that "noninstrumental value claims are often powerful tools for achieving widely endorsed public environmental goals" (p. 75).

${ }^{58}$ Although there is not room to do so here, a complete theory of this type will have to say something, for every particular valuing attitude, about which properties these might be. It will not do simply to say, for example, that the something merits awe because it is awesome - this would leave one with a circular explanation.

59 Thus, I agree with Rabinowicz and Rønnow-Rasmussen, "The Strike of the Demon," and D'Arms and Jacobson, "Sentiment and Value," that we can have prudential reasons for adopting attitudes that are not otherwise warranted; it is not the case that we merely have prudential reasons for wanting to or trying to adopt them.
} 
valuable. It asks you to treat something as though it had a kind of value that you know (at least if you have read your environmental pragmatism lately) that it does not have. Thus, not only does the environmental pragmatist view require a kind of double-consciousness from the point of view of the theoretically enlightened agent, it also presents a picture on which nature does not really merit the treatment that we ought, prudentially, to give it. Thus, while the environmental pragmatist can tell us to value nature intrinsically, he or she cannot say that nature merits intrinsic valuation. As a result, the environmental pragmatist is left with the claim that to treat nature as though it were intrinsically valuable is to make a kind of mistake, though one that it generally benefits us to make. I think that the theoretical approach I sketched above can do better.

In sum, the view of intrinsic value described here is able to avoid treating our attitudes of intrinsic valuation as mistaken just in virtue of the form they take, and for this reason, it allows us a moral psychology that is both familiar and realistic. This conclusion should be no surprise, since it is explicitly formulated to describe the norms that govern this particular moral-psychological type. For this reason, then, I think that environmental ethics should not give up on intrinsic value; nor should any other branch of ethics. It is a concept that plays a critical role in understanding the different ways that we do care about things, and it has a useful role to play in helping us think about the ways we should care about things.

\section{Environmental Ethics Books

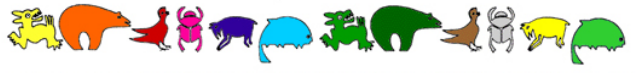

Established in 1990 to help keep important enuironmental philosophy books in print.

The Liberation of Life: From the Cell to the Community

by Charles Birch and John B. Cobb, Jr.

ISBN 0-9626807-0-2, paper: $\$ 21.00$

ix, 353 pages, bibliography, index

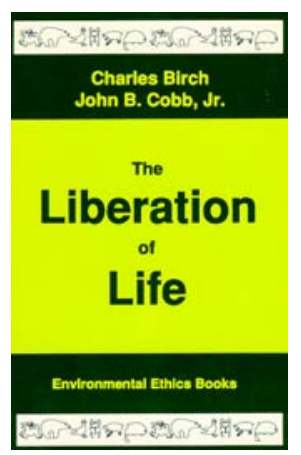

To order by mail, send payment to Environmental Ethics Books, P.O. Box 310980, Denton, TX 76203-0980. Make checks payable to Environmental Ethics in U.S. dollars at a bank in the United States. For MasterCard, Visa, or Discover, provide your name as it appears on the card, the card number, and the expiration date. For faster service, call 940/565-2727 or send a fax to $940 / 565-4439$. Shipping and handling: In the U.S., $\$ 2.00$, book rate; $\$ 4.00$, priority mail. All other countries, $\$ 5.00$, surface mail. Texas residents: add $8.25 \%$ sales tax.

Order Online:

http://www.cep.unt.edu/bookstore 